\title{
Işın tabanlı modellerle en uygun radyo istasyon yeri kestirimi
}

\author{
Mehmet Barış TABAKCIOĞLU* \\ Bursa Teknik Üniversitesi Mühendislik ve Doğa Bilimleri Fakültesi, Elektrik Elektronik Mühendisliği \\ Mimar Sinan Kampüsü, Bursa \\ Geliş Tarihi (Received Date): 10.04.2019 \\ Kabul Tarihi (Accepted Date): 13.01.2020
}

Öz

Servis kalitesi yüksek, güvenilir karasal yayıncılık sistemleri kurmak için baz istasyon yerinin doğru seçilmesi çok önemlidir. Bu işlem için her bir muhtemel baz istasyon yeri üzerinden kapsama alanları çıkarılmakta ve bu haritalar karşılaştırılmaktadır. Binalar ve tepeler baz istasyonundan çıkan ışınların kullanıcıya ulaşmasını engeller. Bu durumlarda elektrik alan Eğim kırınımı (EK) ve Uniform Kırınım teorisi (UKT) modelleriyle bulunabilir. Bu çalışmada EK ve UKT modelleri kullanılarak rasgele yüksekliklere sahip (10x10) 100 engel için en uygun radyo istasyonu yeri tespit edilmiş ve sonuçlar karşılaştırılmıştır.

Anahtar kelimeler: Kapsama alanı haritalanması, UKT modeli, EK modeli, kırınım, dalga yayılımı.

\section{Prediction of optimum radio station place with ray tracing based models}

\begin{abstract}
Deploying of a base station to correct place is vital to install high quality of service $(Q o S)$ and reliable terrestrial broadcasting systems. In order to make this process firstly coverage maps are generated for all possible base station places and then these coverage maps are compared among. Buildings and hills block the rays emanating from the base station to user. In these situations, electric field can be calculated by slope diffraction (S-UTD) and Uniform Theory of diffraction (UTD) models. In this study, optimum radio station place has been determined with S-UTD and UTD models and the results are compared for randomly distributed (10x10) 100 obstacles.
\end{abstract}

\footnotetext{
* Mehmet Barış TABAKCIOĞLU, mehmet.tabakcioglu@btu.edu.tr, https://orcid.org/0000-0002-1607$355 \mathrm{X}$
} 
Keywords: Coverage mapping, UTD model, S-UTD model, diffraction, wave propagation.

\section{Giriş}

Servis kalitesi yüksek, güvenilir karasal yayıncılık sistemleri kurmak için, kullanıcıya ulaşan elektromanyetik dalganın gücünü doğru kestirebilmek çok önemlidir. Cihazların düzgün çalışabilmesi için sinyallerin belirli bir eşik seviyesini aşması gerekmektedir. Bir yere baz istasyonu kurulmadan önce kapsama alanı kestirimi yapmak çok önemlidir. Baz istasyonunun en uygun yere konulması hem harcanan gücü hem de elektromanyetik kirliliği azaltacaktır. Bir bölgedeki kapsama alanı haritasını çıkarmak için Geometrik Optik (GO) ve Uniform Kırınım Teorisi (UKT) modeli gibi 1şın tabanlı yaklaşımlar kullanılabilmektedir [1]. UKT modeli Kouyoumjian ve Pathak tarafindan ileri sürülmüştür [2]. Geometrik optik modeli 1şı̆̆ın tanecik olduğunu kabul edip, yansıma ve kırılma olaylarını açıklamakta fakat 1şığın dalga özelliği olan kırınım olayını açıklayamamaktadır [3]. UKT modeli, yüksek frekans asimptotik bir model olup engel arkasındaki elektrik alanı çok kısa sürede hesaplayabilmektedir. UKT modelinin hatası bina sayısı artınca [4] ve bu binalar birbirinin geçiş bölgesini kestikçe artmaktadır [5]. Eğim kırımı modelinin ileri sürülmesiyle, UKT modelinin hatası büyük ölçüde ortadan kaldırılmıştır [6],[7]. Eğim Kırınımı (EK) modeli bina sayısı 10'dan fazla olduğu durumlarda hatalı sonuçlar vermekte ve çok fazla hesaplama süresi gerektirmektedir. Kapsama alanı haritalanması FEKO [8], ACCURA [9] ve ATOLL [10] gibi bazı paket programlarla da çıkarılabilmektedir. Paket programlar yüksek lisanslama maliyeti bulunmakta ve UKT temelli olduğundan bina yükseklikleri arasındaki farklar düşük ise hatalı sonuçlar vermektedir. Ayrıca paket programlarda belirli sayıda kırınıma izin verilmekte olduğundan kesin bir kapsama alanı elde edilememektedir. Bu makalede engel yükseklikleri yakın olduğunda UKT modelinin hatalı sonuçlar verdiği, bu model yerine EK modelinin daha yüksek bir kesinlikle kullanılabileceği tartışılmıştır. Makalenin devamında GO, UKT ve EK modelleriyle alakalı bilgiler verilmekte, UKT ve EK modelleriyle kapsama alanı haritası çıkarımı ve en uygun radyo istasyonu konumu belirleme benzetimi yapılmakta ve bu modellerin kesinlik ve zaman açısından karşılaştırılması paylaşılmaktadır.

\section{Işın tabanlı modeller}

Bu makalede geometrik optik, uniform kırınım teorisi ve eğim kırınımı modelleri gibi ışın izleme tekniği tabanlı modeller anlatılacaktır.

\subsection{Geometrik optik modeli}

Geometrik optik modeli, doğrudan gelen ve yansıyan 1şınların oluşturduğu elektrik alanı hesaplamada kullanılır. Doğrudan gelen ışından kaynaklanan elektrik alan için aşağıdaki denklem kullanılabilir.

$E=\frac{E_{i}}{s} e^{-j k s}$

Burada, $E_{i}$ alıcı noktası üzerine ulaşan elektrik alan, $k$ dalga sayısı ve $s$ kaynak ile alıcı nokta arası mesafedir. 


\subsection{Uniform kurınım teorisi}

Yayılım senaryosunda alıcı verici pozisyonları arasında bir engel varsa doğrudan gelen 1şınlar alıcıya ulaşamazlar sadece kırınarak gelen 1şınlar alıcıya ulaşabilirler. Bu durumda alıcı pozisyonunda elektrik alan [11] de verilen aşağıdaki formülle bulunabilir.

$E=E_{i} D A(s) e^{-j k s}$

Burada, $E_{i}$ engel üzerine gelen elektrik alanıdır, $D$ genlik kırınım katsayısıdır. $k$ dalga sayısını ifade edip, $A(s)$ dalganın yayılma faktörüdür. $s$ ise engel-alıcı arası mesafedir. Genlik kırınım katsayısı [12] de verilen aşağıdaki formülle denklemle hesaplanabilir.

$D=-\frac{e^{-\frac{j \pi}{4}}}{2 \sqrt{2 \pi k} \cos \left(\frac{\alpha}{2}\right)} F[x]$

Burada, $\alpha$ Şekil 1'den de görülebileceği gibi kırınım açısı olup $F[x]$ ise geçiş fonksiyonu olup 0-1 arası bir sonuç vermektedir. $x=2 k L \cos ^{2}(\alpha / 2)$ olup $L$ genlik kırınımı için uzaklık parametresi ve $k$ dalga sayısıdır.

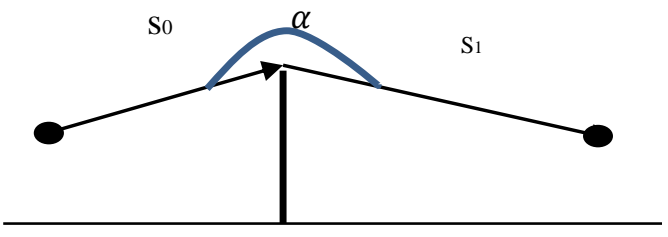

Şekil 1. Kırınım olayı.

Denklem (3)'te görülen $A(s)$ dalganın yayılma faktörü olup aşağıda verilen formülle bulunabilir.

$A(s)=\sqrt{\frac{s_{0}}{s_{1}\left(s_{1}+s_{0}\right)}}$

burada, so verici-engel arası, $s_{1}$ ise engel-alıcı arası mesafedir.

\section{3. Ĕ̈im kırınımı teorisi}

Yayılım senaryosunda alıcı verici pozisyonları arasında bir engel varsa doğrudan gelen 1şınlar alıcıya ulaşamazlar sadece kırınarak gelen 1şınlar alıcıya ulaşabilirler. Bu durumda alıcı pozisyonunda elektrik alan [11] de verilen aşağıdaki formülle bulunabilir.

$$
E=\left[E_{i} D+\frac{\partial E_{i}}{\partial n} d_{s}\right] A(s) e^{-j k s}
$$

Burada, $\frac{\partial E_{i}}{\partial n}$ gelen alanın normale göre türevi ve $d_{s}$ eğim kırınım katsayısıdır. Engel sayısı iki ve daha fazla olduğu durumlarda [11] de verilen eğim kırınım katsayısı kullanılmaktadır.

$d_{s}=-\frac{e^{-\frac{j \pi}{4}}}{\sqrt{2 \pi k}} L_{s} \sin (\alpha / 2)(1-F[x]$

Burada, $\alpha$ Şekil 1'den de görüldüğü üzere kırınım açısı, . $x=2 k L \cos ^{2}(\alpha / 2)$ dir. $F[x]$ geçiş fonksiyonu olup 0-1 arası değer döndürmektedir. $L_{s}$ eğim kırınım katsayısı için uzaklık 
parametresi olup [4] te verilmiştir. Kırınım sayısı üçten fazla olduğu durumlarda eğim kırınım katsayısının normal türevi de kullanılmalıdır.

$\frac{\partial d_{s}}{\partial n}=-\frac{1}{2 s} \frac{e^{-j \pi / 4}}{\sqrt{2 \pi k}}\left\{L_{s} \cos \left(\frac{\alpha}{2}\right)\left[1-F(x)+4 L_{s}^{2} k \sin ^{2}(\alpha / 2) \cos (\alpha / 2) F^{\prime}(x)\right]\right\}$

Burada, $\alpha$ Şekil 1'den de görülebileceği gibi kırınım açısıdır. $F[x]$ geçiş fonksiyonu, $\mathrm{k}$ dalga sayısı, $\mathrm{L}_{\mathrm{s}}$ uzakl1k parametresidir.

\section{Kapsama alanı kestirimi ve optimum radyo istasyonu konumu bulunması}

Herhangi bir bölgedeki kapsama alanı kestirilirken, o bölgedeki tüm noktalarda toplam elektrik alan hesaplanmalıdır. Elektrik alan doğrudan gelen veya kırınarak gelen 1şınlardan oluşabilir. Bu alan GO, UKT ve EK modelleriyle hesaplanabilir. Herhangi bir nokta muhtemel baz istasyonu konumu seçilip diğer tüm noktalar alıcı pozisyonu olarak atanır ve yayılım modelleri kullanılarak bir kapsama alanı haritası oluşturulur. Daha sonra muhtemel verici noktası değiştirilip diğer tüm noktalarda elektrik alan hesaplanır ve kapsama alanı haritası çıkarılır. Sonunda en uygun kapsama alanı otomatik olarak seçilir. Kapsama alanı haritası oluşturmak ve en uygun baz istasyonu konumunu tespit etmek için Şekil 2'de verilen dijital senaryo kullanıldı.

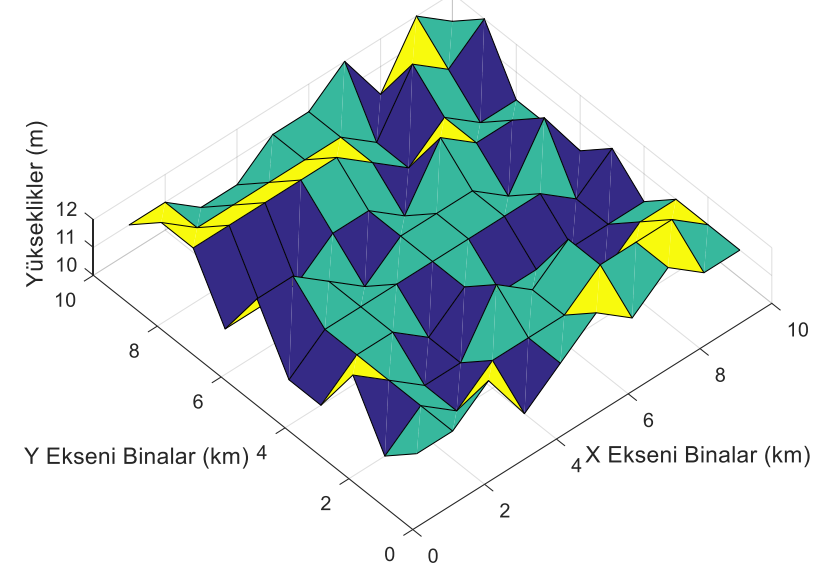

Şekil 2. Dijital arazi haritası.

Şekil 2'de 110 MHz'de yayın yapan bir radyo istasyonu için 90x90 km² lik bir alan gösterilmektedir. Burada yükseklikleri 10-12 m arasında rasgele atanan, Tablo 1'de verilen 100 tepe mevcuttur.

Tablo 1. Senaryodaki tepelerin yükseklikleri.

\begin{tabular}{llllllllll}
\hline 11 & 11 & 12 & 10 & 11 & 12 & 11 & 12 & 11 & 11 \\
10 & 11 & 10 & 11 & 11 & 11 & 12 & 12 & 12 & 11 \\
12 & 11 & 10 & 10 & 12 & 11 & 12 & 10 & 11 & 11 \\
10 & 11 & 11 & 10 & 11 & 10 & 10 & 10 & 10 & 10 \\
10 & 11 & 11 & 11 & 11 & 11 & 11 & 11 & 10 & 11 \\
12 & 12 & 11 & 10 & 11 & 11 & 11 & 10 & 12 & 10 \\
10 & 10 & 10 & 11 & 11 & 10 & 12 & 11 & 11 & 10 \\
12 & 12 & 12 & 12 & 12 & 11 & 10 & 11 & 10 & 10 \\
12 & 11 & 11 & 11 & 11 & 11 & 10 & 12 & 11 & 12 \\
11 & 11 & 10 & 10 & 11 & 11 & 12 & 10 & 12 & 11 \\
\hline
\end{tabular}


Bu çalışmada UKT ve EK modelleri kullanılarak elektrik alanlar hesaplanmaktadır. Hem kapsama alanı hem de hesaplama süresi üzerinden karşılaştırmalar yapılacaktır. İlk olarak, $(\mathrm{x}, \mathrm{y})=(0,0)$ noktası muhtemel radyo istasyonu seçilirse (siyah nokta ile belirtilmiş) EK modeli kullanılırsa kapsama alanı Şekil 3’teki gibi oluşmaktadır.

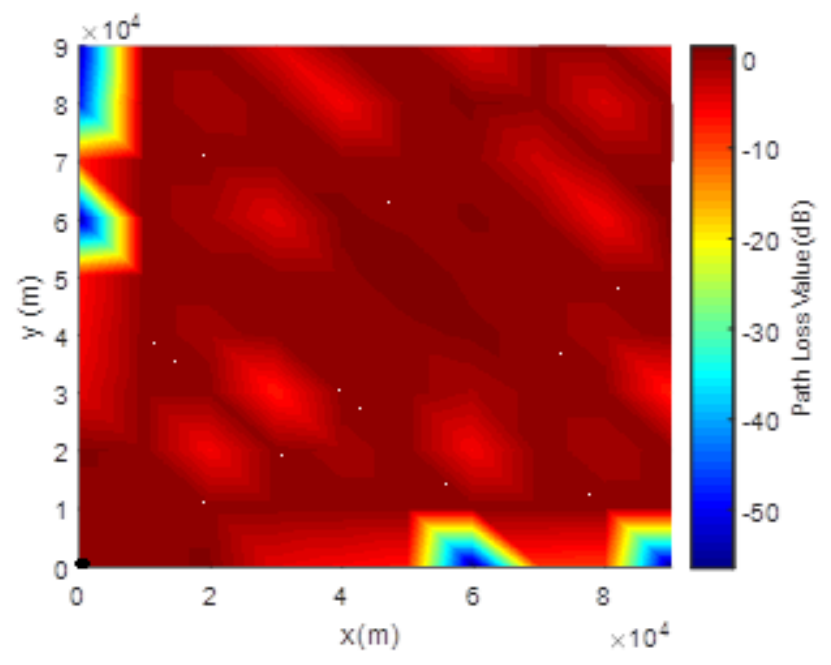

Şekil 3. $(x, y)=(0,0)$ için kapsama alanı $(E K)$.

Şekil 3'te görülebileceği gibi radyo istasyonundan uzaklaştıkça ve/veya kırınım olayı oldukça yol kaybı artmaktadır. Kırınımdan sonra elektrik alan şiddeti çok daha fazla azalmaktadır. Bazı durumlarda engel arkasına doğrudan gelen ışınlar ulaşamadığı ve sadece kırınan 1şınlar ulaştığı için elektrik alan şiddeti -60 dB'e kadar azalmaktadır. Aynı verici pozisyonu için UKT modeli kullanılırsa kapsama alanı Şekil 4'teki gibi oluşmaktadır.

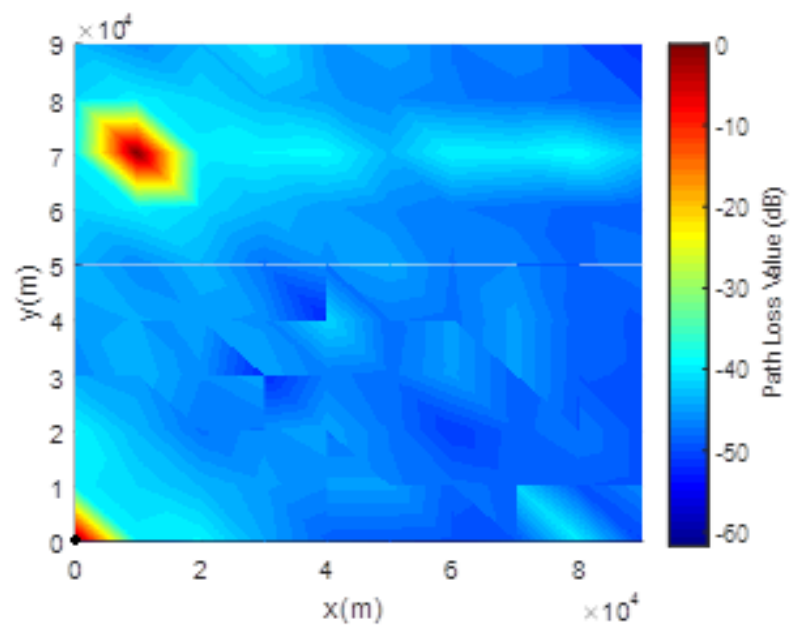

Şekil 4. $(x, y)=(0,0)$ için kapsama alanı (UKT).

Şekil 4'te görülebileceği gibi radyo istasyonundan uzaklaştıkça yol kaybı artmaktadır. UKT modeli çoklu kırınımda engeller birbirinin geçiş bölgesinde olduğu durumlarda hatalı sonuçlar vermektedir. Şekil 3 ile karşılaştırılacak olursa, bölgenin genelinde UKT modeli hatalı sonuçlar vermektedir. Radyo istasyonundan çok kısa mesafede yüksek elektrik alan şiddetine sahiptir. 
İkinci olarak $(\mathrm{x}, \mathrm{y})=(10000,70000)$ muhtemel radyo istasyonu konumu seçilirse (siyah nokta ile belirtilmiş) ve EK modeli kullanılarak kapsama alanı oluşturulursa Şekil 5 'teki sonuçlar elde edilmektedir.

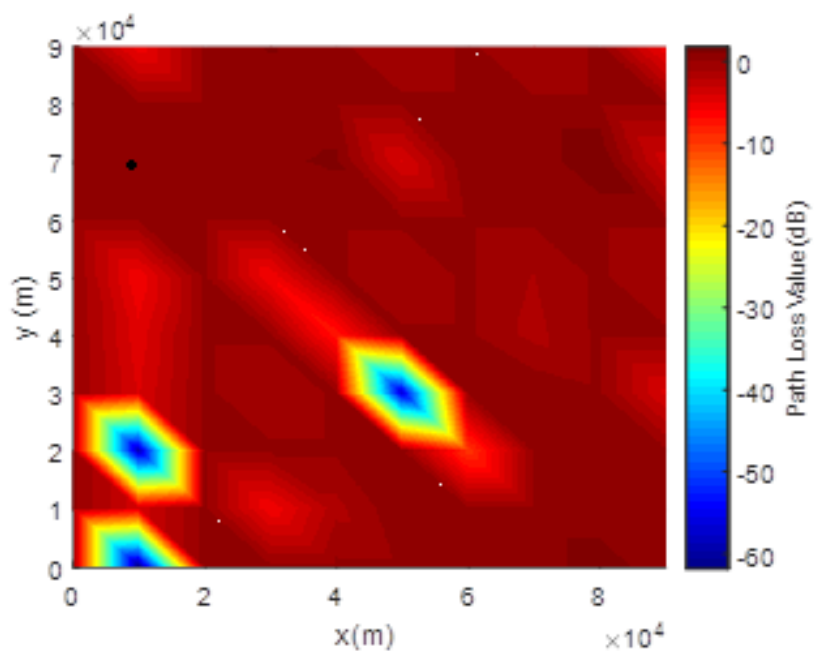

Şekil 5. $(\mathrm{x}, \mathrm{y})=(10000,70000)$ için kapsama alanı $(\mathrm{EK})$.

Şekil 5'te görülebileceği gibi muhtemel radyo istasyonu pozisyonundan uzaklaştıkça yol kaybı artmaktadır. Engel arkasına doğrudan gelen 1şınlar ulaşamadığ i için kırınan alanlar baskın olup elektrik alan şiddeti -62 dB'e kadar azalmaktadır. Aynı verici pozisyonu için UKT modeli kullanılırsa kapsama alanı Şekil 6'daki gibi oluşmaktadır.

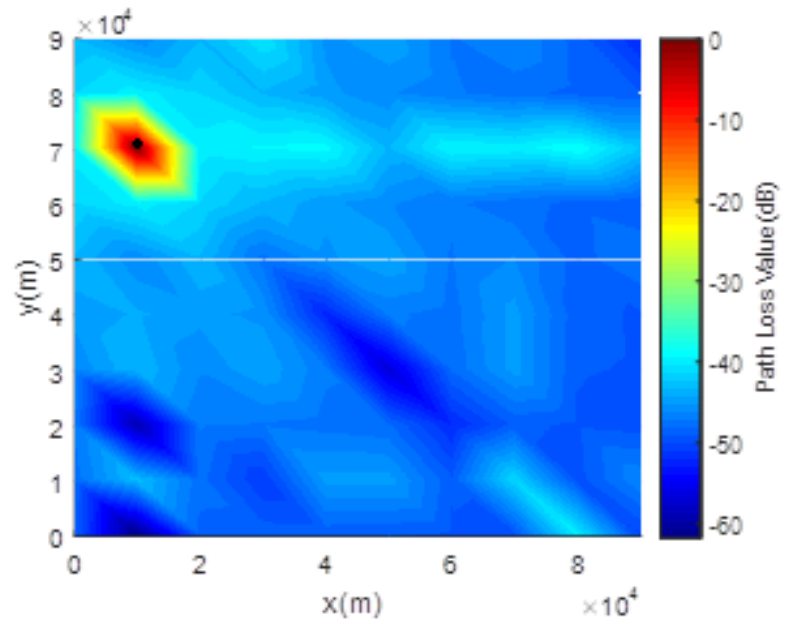

Şekil 6. $(x, y)=(10000,70000)$ için kapsama alanı (UKT).

Şekil 6'da görülebileceği gibi radyo istasyonundan uzaklaştıkça elektrik alan şiddeti azalmaktadır. UKT modeli çoklu kırınımda engeller birbirinin geçiş bölgesinde olduğu durumlarda hatalı sonuçlar vermektedir. Şekil 5 ile karşılaştırılacak olursa, kapsama alanı çıkarılacak bölgenin genelinde UKT modeli hatalı sonuçlar vermektedir. EK modelinde genelde $-10 \mathrm{~dB}$ kapsama alanı elde edilmesine karşın, UKT modelinde engeller birbirinin geçiş bölgesinde olduğu için genelde $-50 \mathrm{~dB}$ civarında kapsama alanı elde edilmiştir.

Son olarak $(\mathrm{x}, \mathrm{y})=(40000,40000)$ seçilirse kapsama alanı Şekil 7'deki gibi oluşmaktadır. 


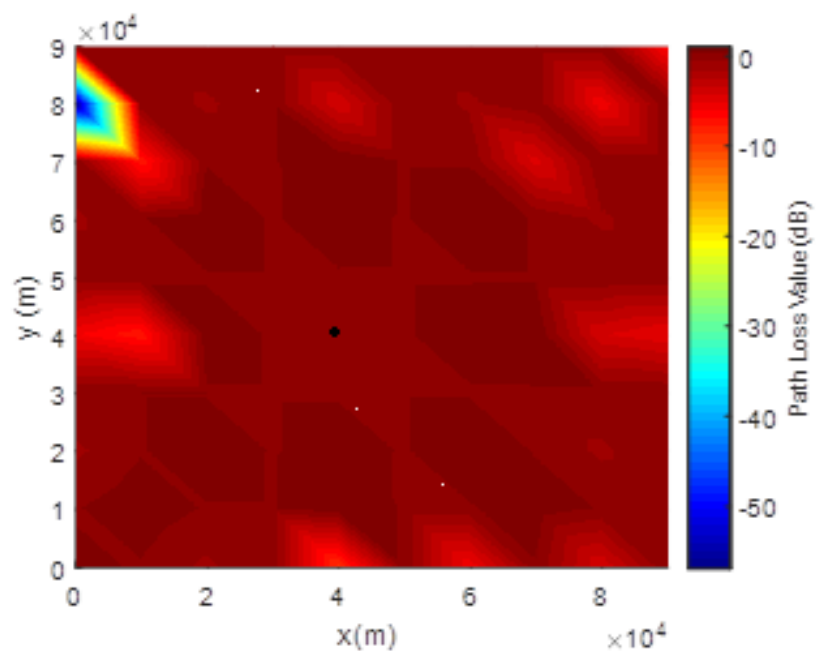

Şekil 7. $(x, y)=(40000,40000)$ için kapsama alanı.

Şekil 7'de görülebileceği gibi muhtemel radyo istasyonu pozisyonundan uzaklaştıkça elektrik alan şiddeti azalmaktadır. Engel arkasına doğrudan gelen 1şınlar ulaşamadığ için kırınan alanlar baskın olup elektrik alan şiddeti -55 dB'e kadar azalmaktadır. Aynı verici pozisyonu için UKT modeli kullanılırsa kapsama alanı Şekil 8'deki gibi oluşmaktadır.

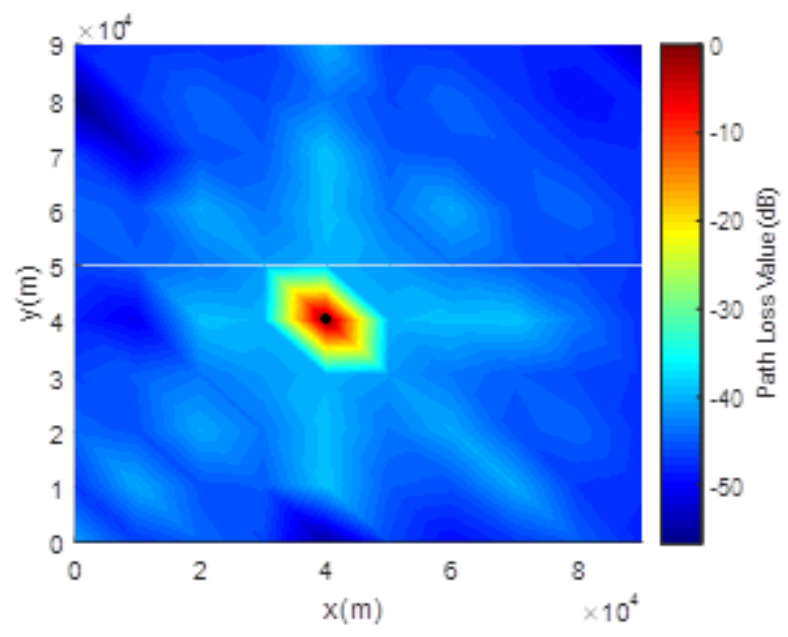

Şekil 8. $(x, y)=(40000,40000)$ için kapsama alanı.

Şekil 8'de görülebileceği gibi radyo istasyonundan uzaklaştıkça yol kaybı artmaktadır. Engeller hemen hemen aynı yükseklikte olduğu için UKT modelinde hesaplanan yol kaybı EK modelindekine (Şekil 7) göre çok daha fazla olmuştur. Birkaç km sonra -60 dB'lere kadar sinyal şiddeti azalmaktadır. EK modelinde genelde $-8 \mathrm{~dB}$ kapsama alanı elde edilmesine karşın, UKT modelinde genelde $-45 \mathrm{~dB}$ civarında kapsama alanı elde edilmiştir.

Bu dijital harita üzerindeki her bir engel üzerine baz istasyonu yerleştirilerek kapsama alanları elde edilmiştir. Matlab ortamında yazılan bir program bu 100 haritayı dikkate alarak en uygun kapsama alanı haritasını otomatik olarak seçmektedir. Her bir baz istasyonu pozisyonu için, renk haritasını oluşturan tüm noktaların elektrik alan şiddetleri kullanılarak haritanın ortalama elektrik alan şiddeti bulunmaktadır. Ortalama elektrik 
alan şiddeti en fazla olan nokta en iyi kapsama alanına sahip olduğu kabul edilmişstir. Dolayısıyla bu nokta en iyi baz istasyonu konumu olarak belirlenmiştir. Şekil 2'de verilen bölge için en uygun radyo istasyonu EK modeli kullanılarak Şekil 9'da görüldüğü gibi seçilmiştir.

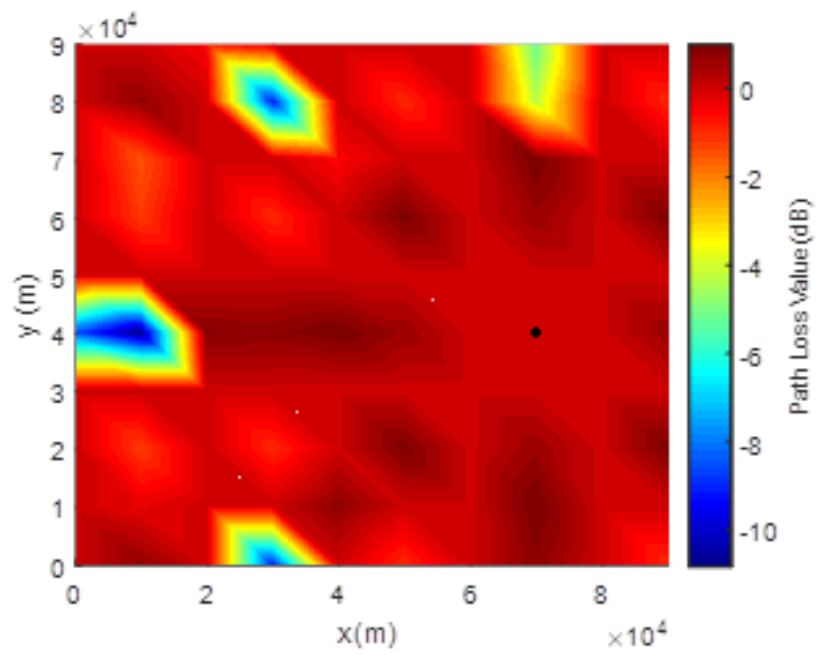

Şekil 9. En uygun radyo istasyon konumu (EK modeli).

Şekil 9'da görüldüğü üzere en uygun radyo istasyon konumu $(\mathrm{x}, \mathrm{y})=(40000,70000)$ konumu seçilmiştir. Bu seçim için hesaplama süresi $93.3 \mathrm{~s}$ ölçülmüştür. En uygun baz istasyonu yeri seçiminde UKT modeli kullanılırsa Şekil 10'daki kapsama alanı en uygun olarak belirlenmiştir.

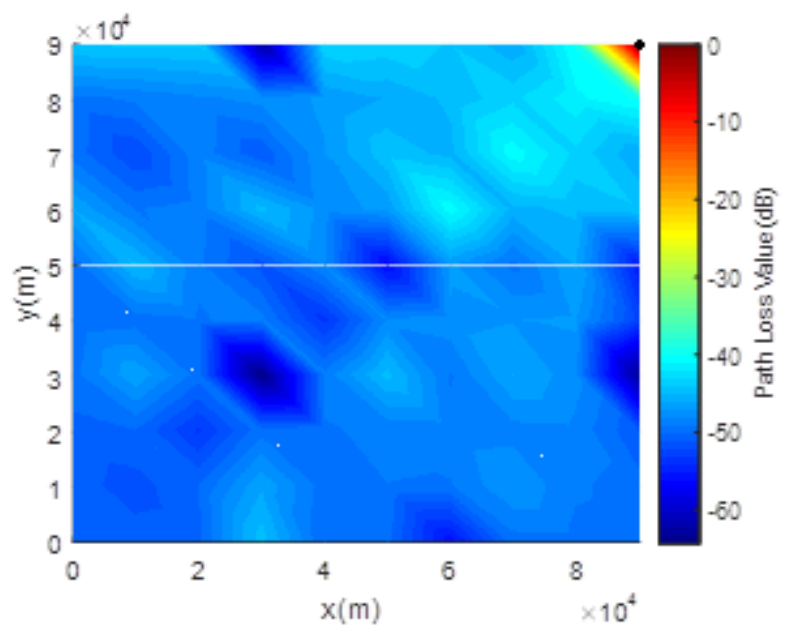

Şekil 10. En uygun radyo istasyon konumu (UKT modeli).

Şekil 10'da görüldüğü üzere en uygun radyo istasyon konumu $(\mathrm{x}, \mathrm{y})=(90000,90000)$ konumu seçilmiştir. Bu seçim için hesaplama süresi $0.36 \mathrm{~s}$ ölçülmüştür. UKT modeli EK modeline göre çok kısa hesaplama süresine sahip olup kestirimdeki kesinliği oldukça düşüktür. 


\section{Sonuçlar}

Güvenilir, etkili, servis kalitesi yüksek ve daha sağlıklı yayın yapan haberleşme ağı kurmak için baz istasyonu konumunu doğru belirlemek çok önemlidir. Kapsama alanı haritalanmasında UKT, GO ve EK modelleri kullanılabilmektedir. UKT modeli EK modeline göre çok kısa sürede hesaplama yapmakta fakat özellikle engel yükseklikleri birbirine yakın olması durumunda çok hatalı sonuçlar vermektedir. Engellerin yükseklikler arasındaki fark yüksek ise UKT modeli kısa hesaplama zamanıyla kullanılabilir. Genel olarak radyo istasyonundan uzaklaştıkça elektrik alan şiddeti azalmaktadır. Eğer senaryoda çok yüksek bir engelden kırınım varsa bağıl yol kaybı çok fazla artmaktadır. Engel yükseklikleri birbirine yakın olduğu için en uygun radyo istasyonu konumu haritadaki toplam elektrik alan şiddetinin en büyük olduğu harita olarak seçilmektedir. İlerleyen çalışmalarda engel yüksekliklerinin farklı olduğu durumlar için en uygun yer tespiti yapılması planlanmaktadır.

\section{Teșekkür}

Bu çalışma TÜBİTAK tarafından 215E360 proje numarası altında desteklenmiştir.

\section{Kaynaklar}

[1] Aydın AE, Tabakcıŏglu MB., Determination of optimum base station location by using UTD model, 26th Signal Processing and Communications Applications Conference (SIU), 1-4, İzmir, (2018).

[2] Kouyoumjian RG and Pathak PH., Uniform geometrical theory of diffraction for an edge in a perfectly conducting surface, Proceedings of IEEE, 62 (11), 14481461, (1974).

[3] Borovikov VA, Kinber BE. Geometrical Theory of Diffraction. Institution of Electrical Engineers, London, UK, (1994).

[4] Tabakcioglu MB, Kara A., On the improvements in the multiple edge transition zone diffraction, IEEE 2nd European Conference on Antennas and Propagation, 1-5, Edinburgh, (2007).

[5] Tabakcioglu MB., S-UTD-CH model in multiple diffractions, International Journal of Electronics, 103 (5), 765-774, (2016).

[6] Andersen JB., UTD multiple-edge transition zone diffraction, IEEE Trans. Antennas and Prop. 45, 1093-1097, (1997).

[7] Rizk K, Valenzuela R, Chizhik, D, Gardiol F., Application of the slope diffraction method for urban microwave propagation prediction, IEEE Vehicular Tech. Conf. 2, 1150-1155, (1998).

[8] https://altairhyperworks.com/ResourceLibrary.aspx?category=Technical\%20Pap ers\&altair_products=Feko $(26.10 .2019)$

[9] http://www.wavecall.com/accura.html (26.10.2019)

[10] https://www.forsk.com/propagation-modelling (26.10.2019)

[11] Tzaras C, Saunders SR, An improved heuristic UTD solution for multiple-edge transition zone diffraction, IEEE Transactions on Antennas Propagation, 49 (12), (2001).

[12] Luebbers RJ., A General, Uniform Double Wedge Diffraction Coefficient, IEEE Transactions on Antennas and Propagation, 39 (1), 8-14, (1989). 